\title{
Extraction of Natural Silk Fibre from Cocoons of Argema mimosae (Lepidoptera: Saturniidae)
}

Boniface Mutua Ngoka $^{1}$, Everlyn Kamene $\mathrm{Nguku}^{1}$, Esther Ndaisi Kioko ${ }^{3}$, Suresh Kumar Raina ${ }^{1}$ and Jones Mulwa Mueke $^{2}$

1. ICIPE-African Insect Science for Food and Health, P.O. Box 30772-00100, Nairobi, Kenya

2. Department of Biological Sciences, Kenyatta University, P.O. Box 43844, Nairobi, Kenya

3. Zoology Department, National Museums of Kenya, P.O. Box 40658, Nairobi, Kenya

\begin{abstract}
In recent years, numerous actions for sustainable exploitation of forest resources have been undertaken, but few deal with commercialization of forest insects. Several tree based insect products, like wild silk, can be linked with forest conservation activities to provide livelihood services of different economic scales to forest dependent people. African wild silkmoth, Argema mimosae Boisduval, is one of the forest insects, a moth in the family of Saturniidae producing wild silk, but there is need for definite procedures for extracting silk fibre from its cocoons. This study evaluated physical characteristics of the $A$. mimosae cocoons and outlined a procedure to extract viable silk fibre for use in silk industry. Cocoons of the $A$. mimosae were collected from natural forest of Arabuko-Sokoke, Kenya ( $\left.3^{\circ} 20^{\prime} \mathrm{S}, 39^{\circ} 55^{\prime} \mathrm{E}\right)$, and others obtained by semi-captive rearing of the silkmoth larvae. The cocoons of $A$. mimosae were described to be silvery in colour, tough and thick with distinctive perforations on the surface and a prominent valve-like opening with loose filaments at one end. The study recorded $120 \mathrm{~min}$ as the optimum boiling time for the cocoons to yield silvery brown silk floss using sodium carbonate $\left(\mathrm{Na}_{2} \mathrm{CO}_{3}\right)$ as the degumming agent. Cocoons boiled in distilled water could not be deflossed into floss, but remained hard and intact, as compared with those of the control, Bombyx mori. This reveals that A. mimosae cocoons can be processed for natural silk fibre production and offer communities adjacent to forests an excellent opportunity to engage in production of natural wild silk.
\end{abstract}

Key words: African wild silkmoth, A. mimosae, cocoons, silk fibre.

\section{Introduction}

Argema mimosae belongs to the moth family, Saturniidae, and has been documented in East Africa as one of Africa's wild silkmoths with potential to produce natural silk [1]. Silk is a protein fibre made by silkworms and is the only natural fibre that is a filament. The fine structure of cocoon filaments from various lepidopteran insects can be classified into two types-porous and compact filaments. Saturniidae insects, including A. mimosae, spin the porous cocoon filament, while Bombyx mori and all other families spin the compact filament [2].

Natural silk consists of two proteins - the filament (fibroin) and the gum (sericin) [3, 4]. Fibroin is a

Corresponding author: Boniface Mutua Ngoka, Ph.D., research field: agricultural entomology. single protein that is insoluble in hot water, and roughly $76 \%$ of its amino acids have nonpolar side chains. Sericin is primarily amorphous and acts as a gum binder to maintain the structural integrity of the cocoon, thus it is more water-soluble than fibroin [5]. This difference makes the gum easily removable from the filaments through several degumming methods without considerable damage to the filaments. These degumming methods include extraction with water under pressure at $115^{\circ} \mathrm{C}$, boiling off in soap or with synthetic or natural alkalis, enzymatic degumming and degumming in boiling acidic solutions [6-8]. Recent studies have shown sodium carbonate as one of the most effective degumming agents on wild silk cocoons, but little is known on how long A. mimosae cocoons can be boiled for effective degumming and good recovery of floss and yarns for making fabrics [9]. 
Physical characteristics of cocoons, like colour, shape and weight, affect the quality of silk fibre. Due to extensive variation in physical appearance and structure exhibited by cocoon shells from wild silkmoths species, it is important to study these characteristics as part of the degumming process. Hence, this study aimed at examining the physical characteristics of $A$. mimosae cocoons and developing a degumming protocol with ideal boiling time to extract silk floss from its cocoons using sodium carbonate and distilled water.

\section{Materials and Methods}

\subsection{Collection of Cocoon Samples}

Cocoons of wild silkmoth A. mimosae were collected for silk fibre extraction from Arabuko-Sokoke forest, located at Kenya's coast $\left(3^{\circ} 20^{\prime} \mathrm{S}, 39^{\circ} 55^{\prime} \mathrm{E}\right)$. The first samples of cocoons were obtained from communities, who had been collecting A. mimosae pupa from the forest for sale. The communities had stored the empty cocoon shells for a half decade, because they had no use for them after removing the pupae for sale. The second samples were obtained from larvae reared in semi-captivity in two continuous rains seasons of April and October 2008, which was less than a year [10]. These sample cocoons are referred to as old and fresh cocoons, respectively, in this study.

\subsection{Observation of the Cocoon Physical \\ Characteristics}

Physical characteristics of the cocoons, such as colour and shape, were observed under the light microscope (Leica model). The weight $(\mathrm{g})$ of the cocoon shells was recorded using a laboratory weighing balance (Scout Pro SPU402). Peculiar holes observed on the surface of the cocoons were counted with a hand-held tally counter under light microscope.

\subsection{Sorting and Boiling of Cocoons}

Healthy cocoons shells were selected, cut open with a sharp surgical blade (size) and cleaned of all pupal debris and other foreign materials [11, 12]. While boiling, cocoons tend to float on the surface of the solution, leading to unequal softening. To ensure homogenous boiling, $50 \mathrm{~g}$ of cleaned cocoon shells were enclosed in wire mesh cages with a volume of $717 \mathrm{~cm}^{3}$ and boiled in aqueous solution of $5 \mathrm{~g} / \mathrm{L}$ of $\mathrm{Na}_{2} \mathrm{CO}_{3}$ (sodium carbonate or Magadi soda) at different boiling intervals of 60,90 and $120 \mathrm{~min}$. After boiling, the cocoons were gently compressed to remove excess water and soaked for $3 \mathrm{~min}$ in a fabric softener (Sta-Soft ${ }^{\circledR}$ fabric conditioner) solution of 50 $\mathrm{mL}$ in $1 \mathrm{~L}$ of distilled water. The fabric softener is a chemical compound that prevents static cling and confers many other desirable properties to laundry, and thus emulsifies the cocoons for easy deflossing. The cocoons were semi-dried at room temperature for $30 \mathrm{~min}$ and kept in a tight clear polythene bag to remain semi-dry. The experiment was replicated three times.

\subsection{Deflossing of Dried Degummed Cocoons and Spinning of Floss}

The semi-dried degummed cocoons were deflossed by hand into floss and kept in a tight polythene bag to maintain it semi-dry before spinning into yarn. The semi-dry floss was spun into yarn using a locally manufactured spinning wheel (diameter $50 \mathrm{~cm}$ ) controlled by hand and powered by foot paddling. An electronic balance (Mettler PJ360, Switzerland) was used to weigh the floss and the yarn.

\subsection{Control Experiment}

A control experiment was conducted simultaneously using distilled water as the degumming agent with same number of replicates. Cocoons of B. mori, which have known silk fibre extraction process and standards, were used for comparison.

\subsection{Statistical Analysis}

Data analysis was done in $\mathrm{R}$ Development Core 
Team [13]. The physical characteristics of cocoons, including diameter and cocoon shell mass, as well as the number of peculiar holes present on cocoon surface, were summarized using descriptive statistics. Means were analyzed using one-way analysis of variance with a PROC analysis of variance procedure. The least significant difference tests $(\alpha=0.05)$ were used to separate means.

\section{Results}

\subsection{Cocoon Physical Characteristics}

A. mimosae cocoons were observed to be silvery in colour, rough and compact with a prominent oval opening at one end. At the opening, there is loose silk fibres forming a brush-like valve at the front tip, from where the moth emerges (Figs. 1 and 2). The mean number of numerous peculiar holes observed on the surface per cocoon was $170.89 \pm 8.16$ with a mean shell weight of $0.71 \pm 0.012 \mathrm{~g}$. There was a non-significant negative correlation between the two variables (correlation coefficient $=-0.0334, P=0.7418)($ Fig. 3$)$.

Further observation was done by scanning microscope to measure the diameter of the silk fibre and the holes. The mean diameter of the peculiar holes was $0.497 \pm 0.02 \mathrm{~mm}$ (Fig. 4).

\subsection{Silk Yarn Yield Produced Using Aqueous Solution of $5 \mathrm{~g} / \mathrm{L}$ of $\mathrm{Na}_{2} \mathrm{CO}_{3}$}

The experiment was based on $50 \mathrm{~g}$ cocoons. The mean number of cocoons of $50 \mathrm{~g}$ ranged between $67.00 \pm 1.00$ to $89.00 \pm 2.31$ and $170.00 \pm 5.57$ to $200.00 \pm 3.93$, for A. mimosae and B. mori, respectively. After boiling the $A$. mimosae cocoons in a solution of $5 \mathrm{~g} / \mathrm{L}$ of $\mathrm{Na}_{2} \mathrm{CO}_{3}$, silvery brown floss was extracted and the yield varied significantly with the increase of the boiling time (Table 1). The maximum silk yield of $35.28 \pm 2.40 \mathrm{~g}$ was recorded at a boiling time of $120 \mathrm{~min}$, and there was not significantly different between the fresh and old cocoons of $A$. mimosae $\left(F_{2,6}=0.323, P>0.05\right)$.

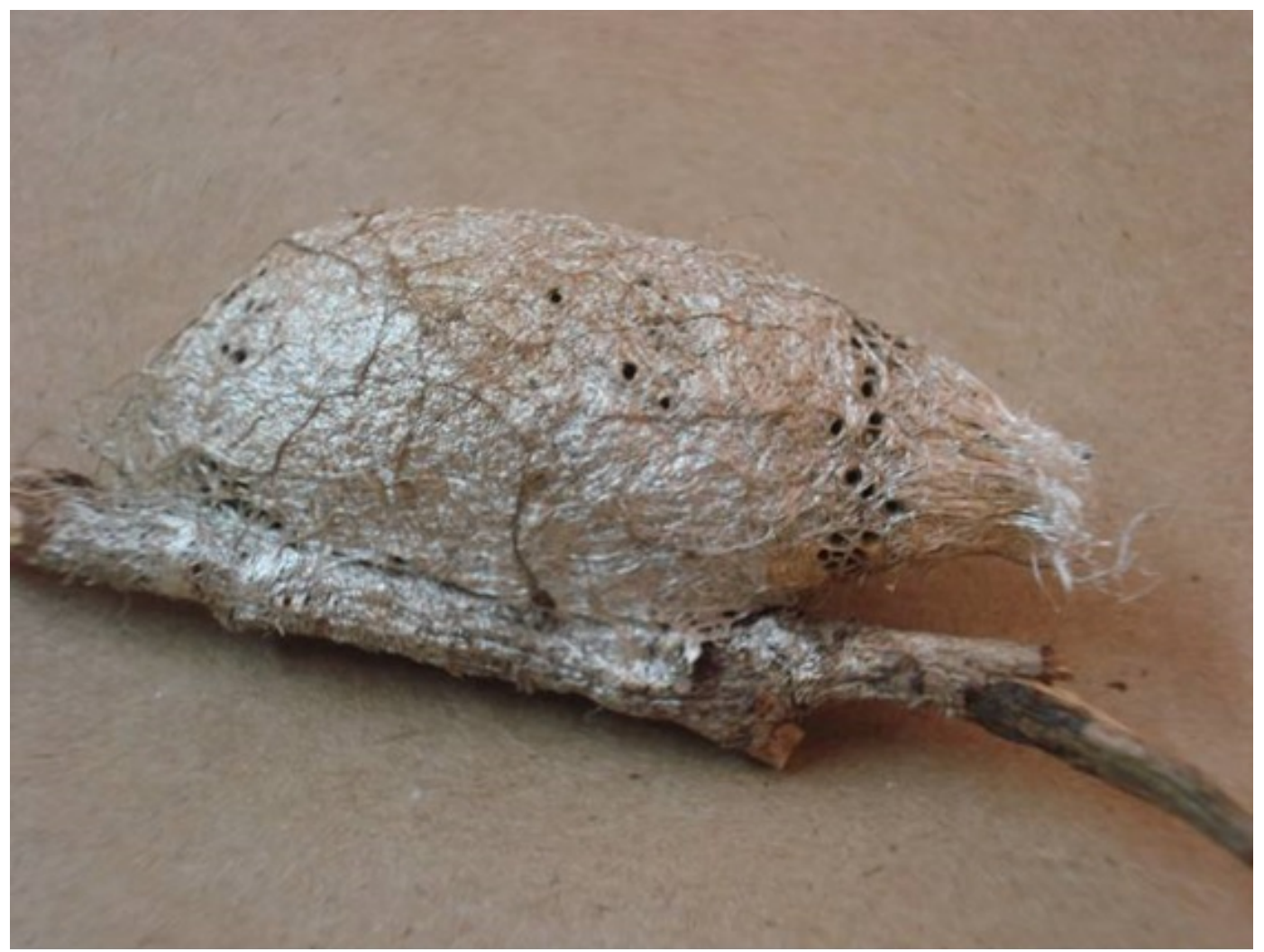

Fig. 1 A. mimosae cocoons embedded on a twig. 


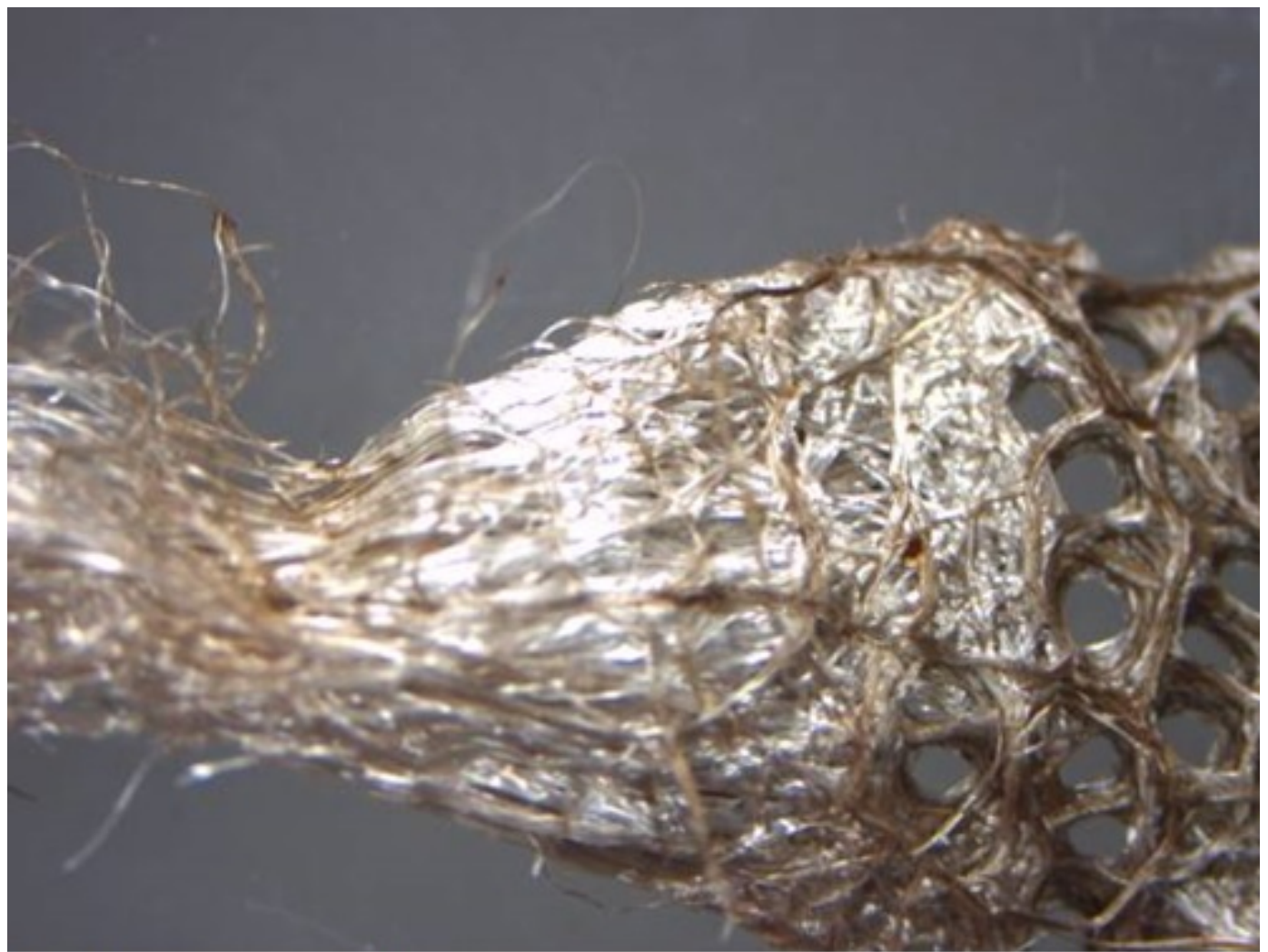

Fig. 2 A cross section of $A$. mimosae cocoons showing the brush like valve and the peculiar holes.

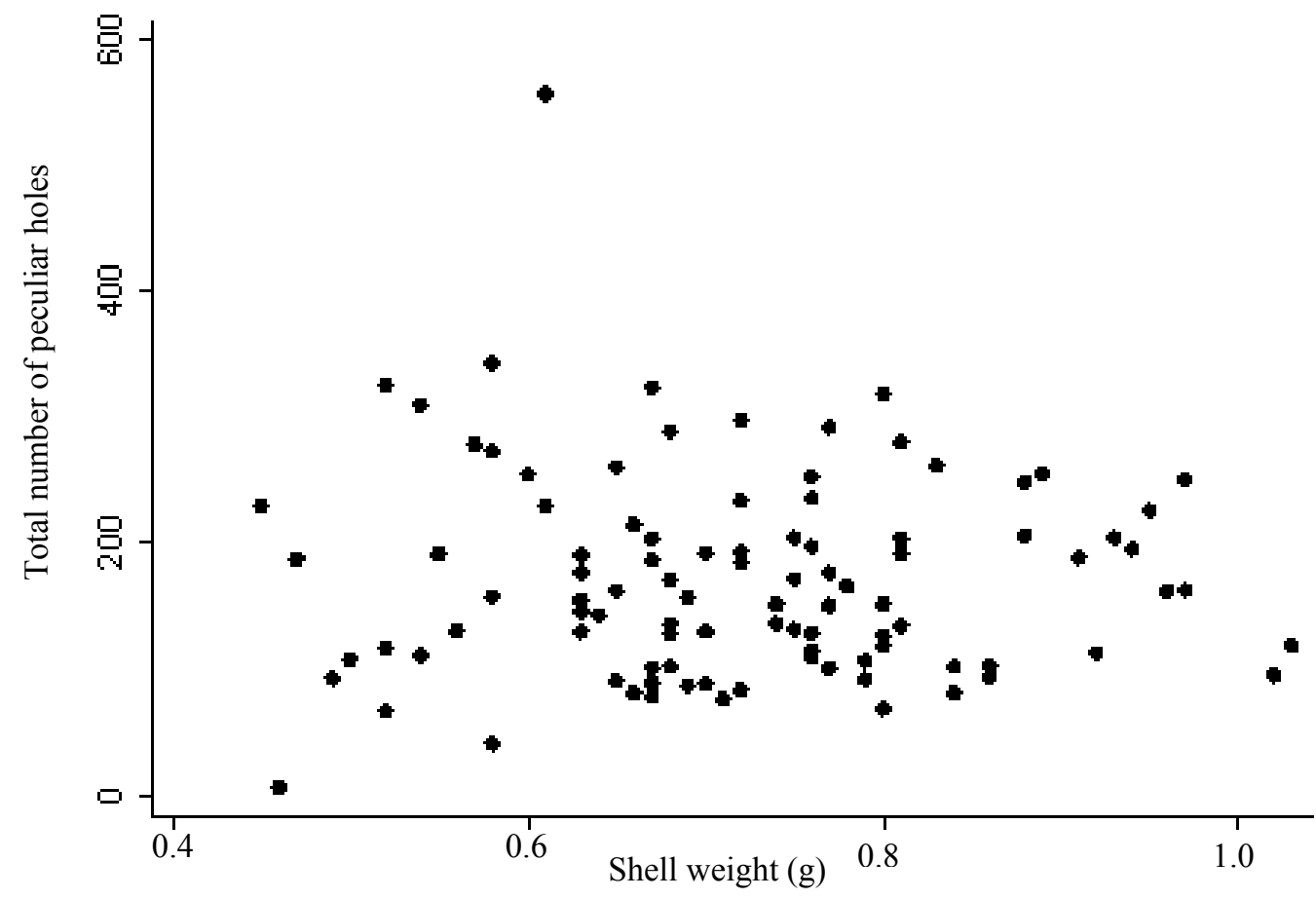

Fig. 3 Correlation of total number of peculiar holes on the cocoon surface and the shell weight. 


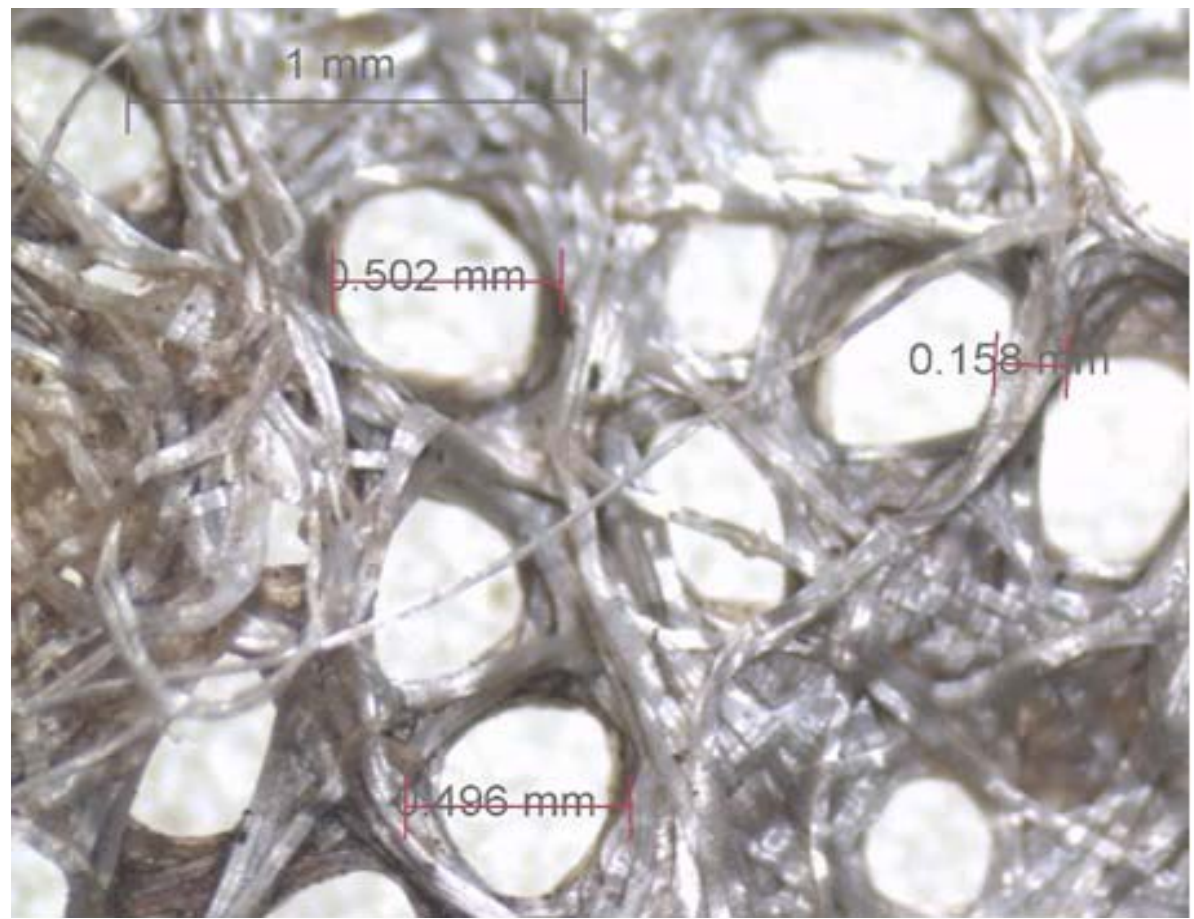

Fig. 4 Across section of $A$. mimosae cocoon surface showing the diameter of the holes.

Table 1 Mean weight of silk yarn produced from $50 \mathrm{~g}$ of cocoons boiled at different time intervals.

\begin{tabular}{|c|c|c|c|c|}
\hline \multirow{2}{*}{ Cocoons } & \multirow{2}{*}{ Boiling time (min) } & \multirow{2}{*}{ Mean number of cocoons } & \multicolumn{2}{|c|}{ Mean yarn weight $(\mathrm{g})$ at different degumming agent } \\
\hline & & & $5 \mathrm{~g} / \mathrm{L}$ of $\mathrm{Na}_{2} \mathrm{CO}_{3}$ solution & Distilled water \\
\hline \multicolumn{5}{|c|}{ A. mimosae } \\
\hline \multirow{3}{*}{ Fresh } & 120 & $77.67 \pm 2.19$ & $33.44 \pm 2.23^{\mathrm{ad}}$ & $0.00 \pm 0.00$ \\
\hline & 90 & $80.33 \pm 1.20$ & $28.89 \pm 1.06^{\mathrm{a}}$ & $0.00 \pm 0.00$ \\
\hline & 60 & $81.00 \pm 3.21$ & $16.87 \pm 0.69^{\mathrm{b}}$ & $0.00 \pm 0.00$ \\
\hline \multirow{3}{*}{ Old } & 120 & $89.00 \pm 2.31$ & $35.28 \pm 2.40^{\mathrm{ad}}$ & $0.00 \pm 0.00$ \\
\hline & 90 & $70.00 \pm 0.58$ & $19.13 \pm 3.69^{\mathrm{b}}$ & $0.00 \pm 0.00$ \\
\hline & 60 & $68.67 \pm 4.18$ & $7.00 \pm 1.22^{\mathrm{c}}$ & $0.00 \pm 0.00$ \\
\hline \multicolumn{5}{|l|}{ B.mori } \\
\hline & 120 & $181.67 \pm 1.20$ & $32.27 \pm 3.24^{\mathrm{adA}}$ & $15.35 \pm 3.88^{\mathrm{aB}}$ \\
\hline & 90 & $200.00 \pm 3.93$ & $34.22 \pm 0.08^{\mathrm{aA}}$ & $2.80 \pm 0.98^{\mathrm{bB}}$ \\
\hline & 60 & $178.33 \pm 3.76$ & $35.95 \pm 0.04^{\mathrm{aA}}$ & $2.65 \pm 0.16^{\mathrm{bB}}$ \\
\hline
\end{tabular}

Means followed by the same lower case letter in the same column and the same upper case letter in the same row are not significantly different (Tukey test $=0.05)$.

While boiling time had no significant effect on the silk yield for B. mori cocoons, as shown in Table $1\left(F_{2},{ }_{6}=\right.$ $0.907, P>0.05)$.

\subsection{Silk Yarn Yield Produced Using Distilled Water}

The cocoons of A. mimosae boiled in distilled water were not deflossed and did not produce yarn regardless of the boiling time. The yield of yarn from B. mori cocoons boiled in distilled water for $60-90$ min was not significantly different, but was highly significant in cocoons boiled for $120 \mathrm{~min}\left(F_{2},{ }_{6}=\right.$ 9.829, $P=<0.01)$. Also, there was a high significant difference in yarn yields between $B$. mori cocoons boiled in sodium carbonate solution and those boiled in distilled water (Table 1).

\subsection{The Linear and Quadratic Effects of Time on Yarn Weight and Their Interaction}

The interaction between boiling time and the cocoon type was also highly significant $\left(F_{2,21}=30.75\right.$, 
$P<0.001)$. Indeed, yarn weight increased linearly with the increasing boiling time for the old and fresh A. mimosae cocoons, while the yarn weight of the $B$. mori cocoons decreased with the increasing boiling time, though the slope of the line was not significantly different from zero (Fig. 5). The estimated parameters of the fitted models are shown in Table 2 .
The fresh cocoons yielded higher weights than the old cocoons below boiling time of $120 \mathrm{~min}$. However, the increase of yarn weight per unit increase of time was higher for the old cocoons (slope of line $=0.47$ ) than for the fresh ones (slope of line $=0.28$ ). It is shown that the old and fresh cocoons could produce approximately the same amount of yarn when boiled for over $120 \mathrm{~min}$ (Fig. 5).

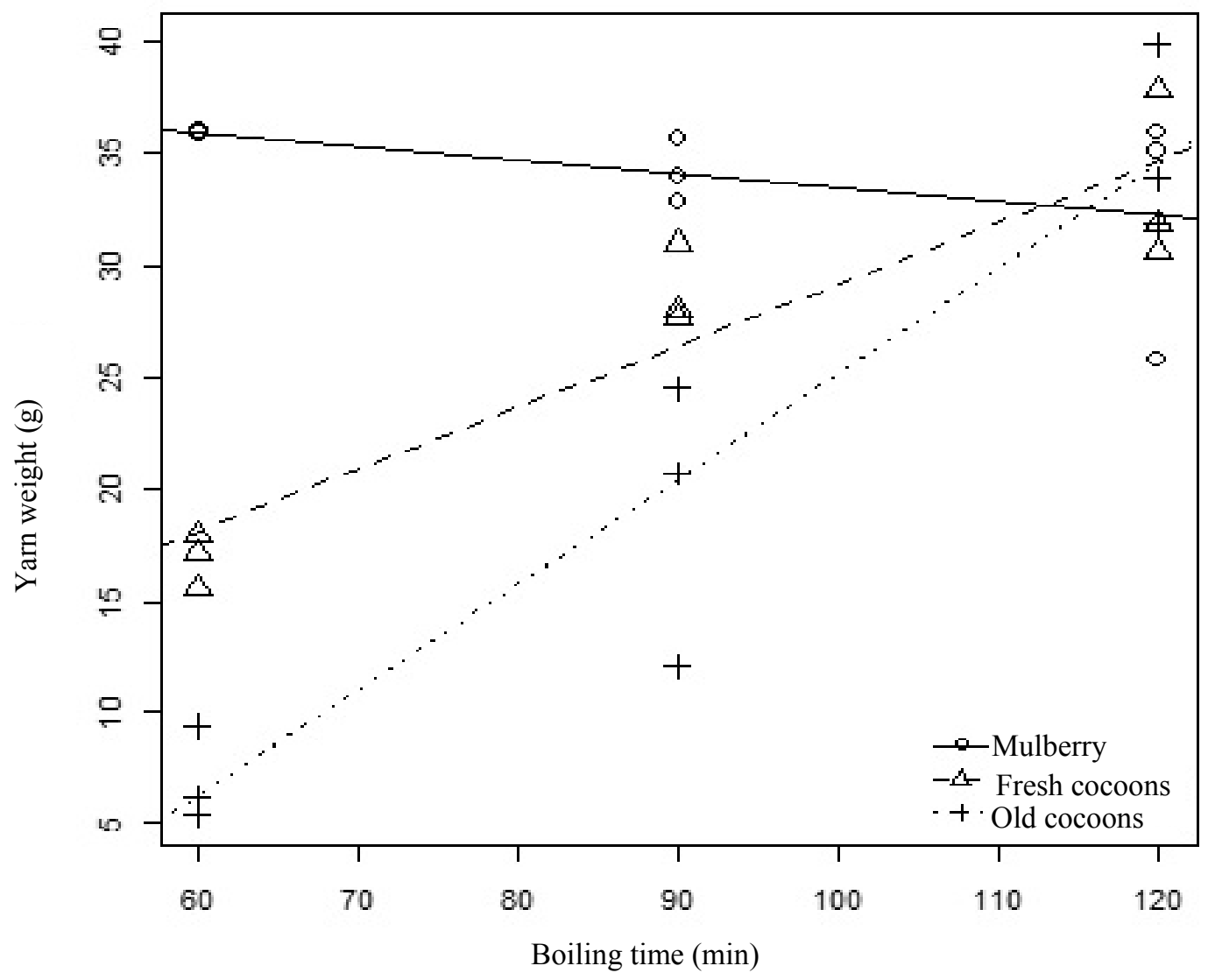

Fig. 5 Observed relationship and fitted regression lines for the relationship between yarn weight and boiling time for fresh and old cocoons of $A$. mimosae and those of $B$. mori.

Table 2 Linear regression parameter estimates for the regression of yarn weight against the boiling time for the different cocoon types.

\begin{tabular}{lll}
\hline Parameter & Estimate & Standard error \\
\hline B. mori & & \\
\hline Intercept & 39.66 & 4.532 \\
Time & -0.06 & 0.049 \\
\hline Fresh cocoon of $A$. mimosae & & \\
\hline Intercept & -38.12 & 6.409 \\
Time & 0.34 & 0.069 \\
\hline Old cocoon of $A$. mimosae & & \\
\hline Intercept & -61.61 & 6.409 \\
Time & 0.34 & 0.069 \\
\hline
\end{tabular}




\section{Discussion}

The results on the physical characteristics of $A$. mimosae cocoons revealed that there were natural perforations observed, which penetrate into the cocoon and are probably for ventilation during the development of the pupa. This is evident from the observation that the holes do not show or suggest any discontinuity in the silk filament and are not associated with parasitoids [11, 14]. Most of the spaces between the filaments in the cocoon shell are filled with sericin, thus allowing no air spaces into the shell, and having these unique holes in the cocoon shell might be useful during ventilation and allow the entry of fresh air from outside [15]. The mean number of peculiar holes observed in this study $(170.89 \pm 8.16)$ conforms to the findings of Akai and Nagashima [15], who reported a range of 100-200 holes in A. mimosae cocoons. The current study also revealed that distribution and the number of holes did not depend on the weight of the shell, but they could determine both the silk fibre quality and quantity [16]. The $A$. mimosae cocoons could not be reeled, because the tips had opening with brush like filaments, where moths emerge. Several filaments ended at the tip individually, thus making the cocoon not reelable. Earlier reports show that cocoons of A. mimosae could not be reeled, but could be spun [16]. After dissection of the cocoons, it was observed that the pupa lay inside the shell with the mouth parts facing the valve surrounded by the loose filaments. This proved the importance of this opening, which is left when the larva is spinning the cocoon.

Degumming using aqueous solution of $5 \mathrm{~g} / \mathrm{L}$ of $\mathrm{Na}_{2} \mathrm{CO}_{3}$ produced silvery brown floss, and the amount of sericin probably gave it a harsh and stiff feeling. Sericin also prevents the penetration of dye liquor and other solutions during wet processing, so silk degumming with an alkali is an essential process to obtain an ideal fiber for the textile industry [17]. Sometimes soap or synthetic detergent must be added in order to improve the degumming effect. Degumming with acid, such as hydrochloric acid and citric acid, has not received much attention in silk industry, since alkaline solution is safer for fibroin than acids [5]. The ideal time for degumming the $A$. mimosae cocoons with alkali solution was $2 \mathrm{~h}$ (120 $\mathrm{min})$. There is a risk of fibroin being damaged when the time of boiling is prolonged, or incomplete degumming when the time inadequate [17]. The $A$. mimosae cocoons probably have strong bonds of sericin gum, explaining the reason why the cocoons were not softened for possible deflossing after boiling with plain water at different time intervals. This was evidenced by comparing its cocoons with those of $B$. mori which produced considerable floss with the same treatment. From these results, it can be concluded that A. mimosae cocoons can be processed using degumming agents, such as sodium carbonate at an optimal boiling time of $120 \mathrm{~min}$. This is ideal compared with plain water method which did not soft the cocoons at all.

\section{Conclusions}

Many people consider insects only from the point of the damage they cause as crop pests and disease vectors; however, this study shows that $A$. mimosae cocoons have the potential to be exploited for commercial purposes to produce forest silk for income generation and poverty alleviation. The degumming process of A. mimosae cocoons outlined in this study can be applied in other wild silk moth species found in different parts of the world to develop forest silk technology as a rural cottage industry and enhance biodiversity conservation. Through the use of commercial insects, such as the $A$. mimosae, and community participation in utilizing the forest resources sustainably, could enhance the income of resource poor rural communities and ensure that the rich biological diversity is conserved [18]. 


\section{Acknowledgments}

The authors express their sincere thanks to International Fund for Agricultural Development (IFAD) and Global Environmental Facility (GEF) for providing financial support, as well as thanks to International Centre of Insect Physiology and Ecology (ICIPE) management for providing facilities and logistical assistance. They are also grateful to Ms. Alice Kasika and Mr. Edward Mwakombe for allowing the study to be carried in their farms adjacent to Arabuko-Sokoke Forest.

\section{References}

[1] Kioko, E. N., Raina, S. K., and Mueke, J. M. 2000. "Survey on the Diversity of Wild Silkmoth Species in East Africa." East African J. Sci. 2: 1-6.

[2] Kavane, R. P., and Sathe, T. V. 2011. Wild Silk Technology. New Delhi: Daya Publishing House.

[3] Akai, H. 2000. "Cocoon Filament Characters and Post-Cocoon Technology.” Int. J. Wild Silkmoth and Silk 5: 71-84.

[4] Mondal, M., Trivedy, K., and Kumar, S. N. 2007. "The Silk Proteins, Sericin and Fibroin in Silkworm, Bombyx mori Linn.: A Review." Caspian J. Env. Sci. 5 (2): 63-76.

[5] Karmakar, S. R. 1999. Chemical Technology in the Pre-treatment Process of Textiles. New York: Elsevier.

[6] Mamedov, S. V., Aktas, B., Canturk, M., Aksakal, B., Alekperov, V., Bulbul, F., Yilgin, R., and Aslanov, R. B. 2002. "The ESR Signals in Silk Fibroin and Wool Keratin under Both the Effect of UV-Irradiation and without Any External Effects and the Formation of Free Radicals." Biomaterials 23 (16): 3405-12.

[7] Dube, S., Khumalo, M. T., Torto, N., and Nyati, J. A. 2006. "Characterization of Amino Acids in Silk Sericin Protein from Gonometa rufobrunnea by MEKC with Phenyl Isothiocyanate Derivatization.” J. Sep. Sci. 29 (9): 1245-50.

[8] Arami, M., Rahimi, S., Mivehie, L., Mazaheri, F., and Mahmoodi, N. M. 2007. "Degumming of Persian Silk with Mixed Proteolytic Enzymes." J. Appl. Polymer Science 106 (1): 267-75.

[9] Rajkhowa, R., Gupta, V. B., and Kothari, V. K. 2000. "Tensile Stress-Strain and Recovery Behaviour of Indian Silk Fibers and Their Structural Dependence." J. Appl. Polym. Sci. 77 (11): 2418-29.

[10] Ngoka, B. M., Kioko, E. N., Raina, S. K., and Mueke, J. M. 2008. "Semi-captive Rearing of African Wild Silkmoth Gonometa postica (Lepidoptera: Lasiocampidae) on an Indigenous and a Non-indigenous Host Plant in Kenya.” Int. J. Trop. Insect Sci. 27 (3-4): 183-90.

[11] Fening, K. O., Kioko, E. N., Raina, S. K., and Mueke, J. M. 2008. "Parasitoids of the African Wild Silkmoth, Gonometa postica (Lepidoptera: Lasiocampidae) in the Mwingi Forests, Kenya.” J. Appl. Entomol. 133 (6): 411-5.

[12] Teshome, A., Raina, S. K., Vollrath, F., Kabaru, J. M., Onyari, J., and Nguku, E. 2011. "Study on Weight Loss and Moisture Regain of Silk Cocoon Shells and Degummed Fibers from African Wild Silkmoths." $J$. Entomol. 8 (5): 450-8.

[13] R Development Core Team. 2009. "A Language and Environment for Statistical Computing." R Foundation for Statistical Computing, Vienna, Austria. Accessed September 10, 2015. http://www.R-project.org.

[14] Veldtman, R., Mcgeoch., M. A., and Scholtz, C. H. 2004. "Parasitoids of Southern Africa Wild Silk Moths (Lepidoptera)." African Entomol. 12 (1): 117-22.

[15] Akai, H., and Nagashima, T. 2002. "Structural Characteristics of Cocoon Filament of the Silkmoth, $A$. mimosae." Int. J. Wild Silkmoths and Silk 7: 47-52.

[16] Raina, S. K. 2001. The Economics of Apiculture and Sericulture Modules for Income Generation in Africa. Cardiff, UK: International Bee Research Association Press.

[17] Gulrajani, M. L. 1992. "Degumming of Silk." Review Programme in Colouration 22: 79-89.

[18] Raina, S. K., Kioko, E. N., Gordon, I., and Nyandiga, C. 2009. Commercial Insects and Forests Conservation: Improving Forest Conservation and Community Livelihoods through Income Generation from Commercial Insects in Three Kenyan Forests. Nairobi: ICIPE Science Press. 